\title{
MASS SPECTROMETRIC IDENTIFICATION OF INTERMEDIATES IN THE BIOSYNTHESIS OF CYANOGENIC GLUCOSIDES
}

\author{
by \\ BIRGER LINDBERG MØLLER \\ Department of Physiology, Carlsberg Laboratory \\ Gamle Carlsberg Vej 10, DK-2500 Copenhagen Valby \\ and \\ ERIC E. CONN \\ Department of Biochemistry and Biophysics \\ University of California, Davis, California 95616 \\ and \\ CHARLES C. SWEELEY \\ Department of Biochemistry, Michigan State University \\ East Lansing, Michigan 48824
}

Keywords: Gas liquid chromatography-mass spectrometry, trimethylsilylation, amino acids, $N$-hydroxyamino acids, aldoximes, ketoximes, nitriles, aldehydes

\begin{abstract}
Mass spectra of trimethylsilyl derivatives of the following compounds, which are related to the biosynthesis of the cyanogenic glucoside dhurrin, are described: tyrosine, $N$-hydroxytyrosine, $p$-hydroxyphenylacetaldoxime, $p$ hydroxyphenylacetonitrile, $p$-hydroxybenzaldehyde, tyramine, $p$-hydroxyphenylpyruvic acid oxime, and $p$ hydroxyphenylpyruvic acid. Accurate mass measurements and metastable transitions support the proposed fragmentation mechanisms. Based on the mass spectrometry data presented, a method is described by which compounds possibly involved as intermediates in the biosynthesis of cyanogenic glucosides can be identified in biosynthetic reaction mixtures.
\end{abstract}

Abbreviations: GLC-MS = gas liquid chromatography-mass spectrometry, TLC $=$ thin layer chromatography, TMS = trimethylsilyl. 


\section{INTRODUCTION}

Studies on the biosynthesis of the tyrosinederived cyanogenic glucoside dhurrin, by use of a microsomal system obtained from etiolated sorghum seedlings have shown that the major part of the intermediates are hydroxylated species containing several functional groups (Figure 1). Thus, upon administration of radioactively labelled L-tyrosine to the microsomes, label can be recovered in $p$-hydroxyphenylacetaldoxime, $p$-hydroxyphenylacetonitrile, and $p$-hydroxybenzaldehyde $(12,17,24)$. $p$-Hydroxybenzaldehyde is formed by enzymatic or nonenzymatic decomposition of $p$-hydroxymandelonitrile, the cyanohydrin of $p$-hydroxybenzaldehyde (23). Identification of these different compounds was based on their thin layer chromatographic behavior and on recrystallisa-

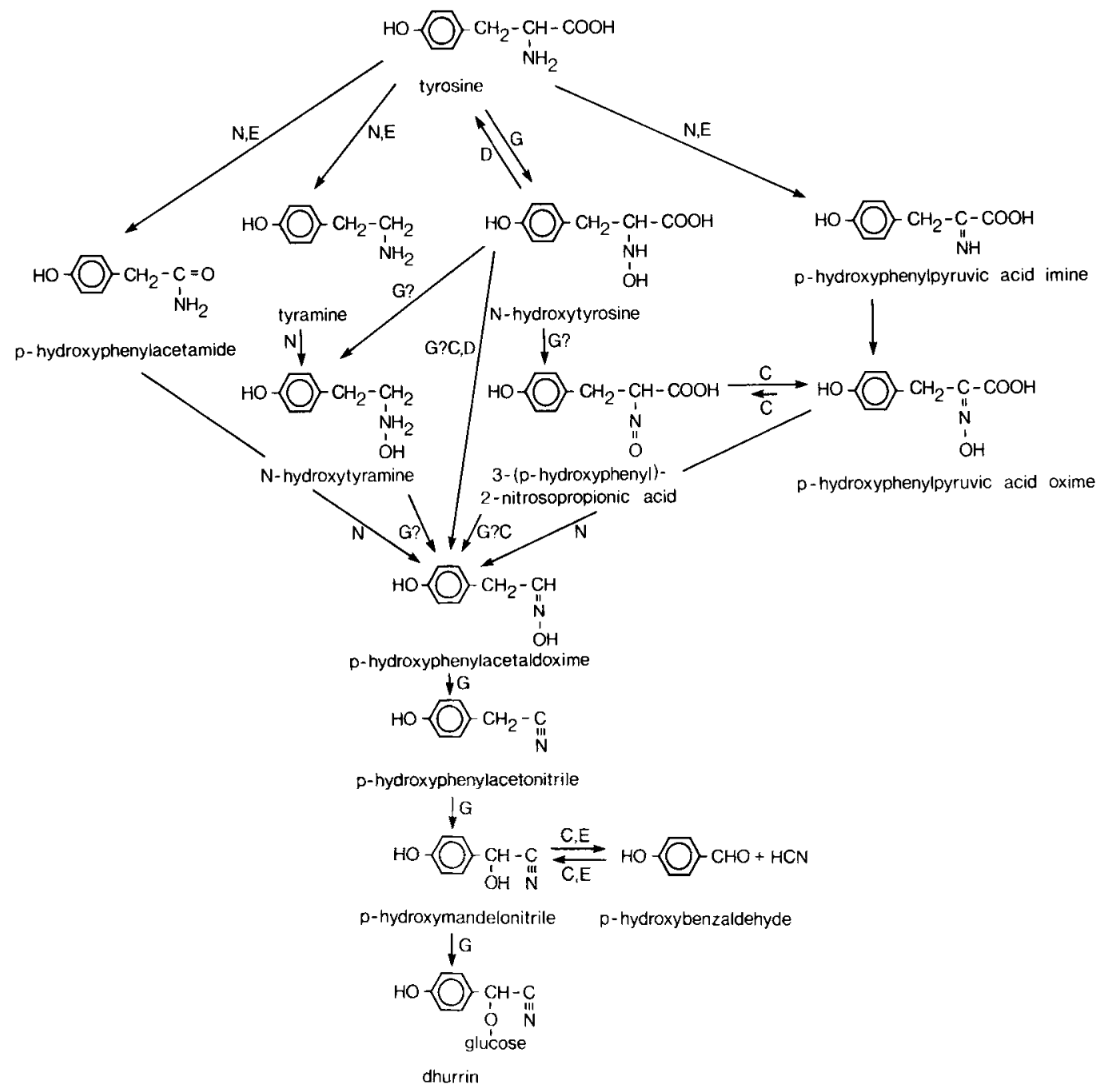

Figure 1. Various hypothetical routes for the biosynthesis of the cyanogenic glucoside dhurrin in Sorghum bicolor (Linn) Moench.

The information available on the nature of the different transformations is as follows: G, enzymatic transformation taking place in the conversion of L-tyrosine into dhurring according to $(17,22,23,24) . \mathrm{N}$, processes excluded in the transformation of L-tyrosine into dhurrin according to metabolic analyses $(17,19)$. E, standard enzymatic transformation $(8,10,13,14,25,26)$. C, chemical transformation (non-enzymatic) (16). D, chemical transformation by dismutation (non-enzymatic) (20). 
tion of each labelled compound to constant specific activity after addition of an unlabelled authentic standard $(12,24)$. When large amounts of unlabelled $N$-hydroxytyrosine were added to the microsomal reaction mixtures, the accumulation of labelled $N$-hydroxytyrosine was also observed (17). Identification of the labelled material was based on its gas chromatographic behavior and on recrystallisation to constant specific activity with authentic $N$-hydroxytyrosine $(15,17)$.

$N$-hydroxytyrosine is an unstable compound. During thin layer chromatography it decomposes into $p$-hydroxyphenylacetaldoxime (16). When refluxed in water under a nitrogen atmosphere, tyrosine and $p$-hydroxyphenylacetaldoxime are obtained (20). These decomposition products are already established intermediates in the pathway $(17,24)$. To avoid ambiguous results from biosynthetic experiments, an analytical procedure based on separation by gas chromatography of the stable trimethylsilyl derivatives of the known intermediates was developed (15). Also $p$-hydroxyphenylpyruvic acid oxime and tyramine, both of which belong to classes of compounds which have been suggested as intermediates in cyanogenic glucoside biosynthesis $(2,3)$, can be analyzed by the use of this procedure. It is the purpose of this paper to describe the electron impact ionization mass spectra of these trimethylsilyl derivatives, and to demonstrate that mass spectrometry can be used in unambiguous identification of intermediates in the biosynthesis of cyanogenic glucosides.

\section{MATERIALS AND METHODS}

\subsection{Chemicals}

All compounds used for the mass spectrometry studies were chemically pure and were synthesized or obtained commercially as earlier described $(17,20)$. The trimethylsilyl derivatives were prepared by reacting the compounds at $90{ }^{\circ} \mathrm{C}$ for $20 \mathrm{~min}$ with $\mathrm{N}, \mathrm{O}$-bis-(trimethylsilyl)trifluoroacetamide (BSTFA) containing $1 \%$ trimethylchlorosilane (TMCS) and with acetonitrile as a solvent (15).

\subsection{Microsomal preparations and biosynthetic experiments}

Microsomal preparations were obtained from the Sorghum bicolor (Linn) Moench hybrid Sordan 70 (Northrup, King and Company, Lubbock, TX) as earlier described (17). Two different preparations were made: the first containing $10 \mathrm{~mm} \beta$-mercaptoethanol in all buffers used, the second with no $\beta$-mercaptoethanol added. The microsomal preparations

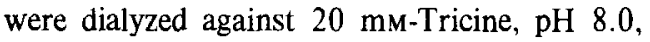
for 30 hours, the first preparation under nitrogen, the second in a normal atmosphere. Biosynthetic experiments were carried out in incubation mixtures containing $3.6 \mathrm{mg}$ of microsomal protein, $0.18 \mu$ moles of L-tyrosine, a NADPH regenerating system $(0.3 \mu$ moles of $\mathrm{NADP}^{+}, 1.0 \mu$ mole of glucose- $6-\mathrm{P}$, and $3 \mathrm{U}$ of glucose-6-P dehydrogenase), 8 moles of $\beta$ mercaptoethanol, and $16 \mu$ moles of Tricine in a total volume of $800 \mu \mathrm{l}, \mathrm{pH} 8.0$. The accumulation of intermediates was followed in parallel experiments where ${ }^{14} \mathrm{C}$-labelled tyrosine was used as the substrate. At various time periods $(15,30$, and $60 \mathrm{~min})$ aliquots $(250 \mu \mathrm{i})$ were pipetted into ampules $(1 \mathrm{ml})$. The enzyme reaction was immediately stopped by immersing the ampules in liquid nitrogen and their contents were lyophilised to dryness. After preparing the trimethylsilyl derivatives the composition of the isotope containing reaction mixture was determined by use of a gas chromatograph coupled to a gas proportional counter (15). $p$-Hydroxybenzaldehyde was preferentially produced by using the microsomes prepared in the presence of $\beta$ mercaptoethanol as it has previously been shown $(12,17)$ that these conditions favor the synthesis of this compound. $p$-Hydroxyphenylacetaldoxime was obtained in about $70 \%$ yield by using the microsomes prepared without added $\beta$ mercaptoethanol. The low amounts of $p$-hydroxyphenylacetonitrile produced in these preparations were also used for analysis. No $\mathrm{N}$ hydroxytyrosine accumulated under these conditions.

Samples for analysis by gas liquid chromatography-mass spectrometry (GLC-MS), obtained from enzymatic experiments using L-tyrosine as substrate, were prepared by pipetting aliquots $(250 \mu \mathrm{l})$ into $800 \mu \mathrm{l}$ ethyl acetate to stop the enzyme reaction. All of the tyrosine metabolites 
formed in the biosynthetic reaction mixture were extracted quantitatively into ethyl acetate by three repeated extractions of the reaction mixture with $0,2 \mathrm{ml}$ portions of ethyl acetate. This is possible because parallel experiments with $\mathrm{L}\left\{\mathrm{U}-{ }^{14} \mathrm{C}\right]$ tyrosine showed that the water soluble $N$-hydroxytyrosine did not accumulate at any of the time periods tested. The combined ethyl acetate extracts were concentrated to a small volume under a gentle stream of nitrogen and applied to Bakerflex silica gel TLC plates which were then developed in benzene-ethyl acetate $(5: 1, v / v)$ as earlier described (17). The areas of the TLC plates which from the parallel experiment with [U-14C]-tyrosine were known to contain intermediates were scraped off, eluted with ethanol, and the clarified organic phases obtained after centrifugation were evaporated to dryness under nitrogen. Residual amounts of $\mathrm{H}_{2} \mathrm{O}$ were removed by lyophilization and the dry samples trimethylsilylated and analyzed by GLC-MS.

\subsection{Measurement of mass spectra, instrumentation}

Mass Spectra were obtained by GLC-MS on an LKB-9000 instrument under the following conditions: accelerating voltage, $3.5 \mathrm{kV}$; electron energy, $80 \mathrm{eV}$; electron current, $60 \mu \mathrm{A}$; ion source temperature, $290^{\circ} \mathrm{C}$. The trimethylsilyl derivatives were separated on $3 \%$ SP-2100 on 80-100 mesh Supelcoport ( $2.5 \mathrm{~m} \times 3 \mathrm{~mm}$ i.d.). The temperature of the GLC column was kept at $150{ }^{\circ} \mathrm{C}$ for $6 \mathrm{~min}$ after the sample was injected, then increased rapidly $\left(30^{\circ} \mathrm{C} / \mathrm{min}\right)$ to $185^{\circ} \mathrm{C}$, and held at that temperature for the remainder of the analysis. Direct probe analyses and exact mass measurements were obtained on a Varian MAT CH-5 double focusing instrument. The high resolution measurements were performed in the 0 to 10.000 range using perfluorokerosene as the reference.

\section{RESULTS AND DISCUSSION}

The structures of TMS derivatives of compounds implicated in the biosynthesis of the cyanogenic glucoside dhurrin were determined from their mass spectra after separation by gasliquid chromatography (Table I). Most of the
TMS derivatized compounds contain more than one TMS group. Several possibilities exist for the localisation of the positive charge on the molecular ion resulting in different fragmentation patterns. Only those routes which are necessary to explain a possible origin of the major fragment ions are illustrated (Scheme 1 to 6). The molecular ion $[\mathrm{M}] \pm$ is observed in all the mass spectra. The mass spectra of all TMS derivatives except that of $p$-hydroxyphenylacetaldoxime show a comparatively more intense fragment ion at $[\mathrm{M}-15]^{+}$. This ion is formed from the molecular ion $[\mathrm{M}] \pm$ by the loss of a methyl radical and is characteristic for TMS derivatives (21). In all the mass spectra, frag. mentation pathways typical of TMS groups resulted in peaks at $\mathrm{m} / \mathrm{e} 73,75$ and 147 , representing ${ }^{+} \mathrm{SiMe}_{3}, \quad \mathrm{HO}^{+}=\mathrm{SiMe}_{2}$, and $\mathrm{Me}_{2} \mathrm{Si}=0^{+}-\mathrm{SiMe}_{3}$ (siloxonium ion), respectively $(4,5)$.

The mass spectrum of $p$-hydroxybenzaldehyde-TMS (Figure 2) displays a prominent ion at $\mathrm{m} / \mathrm{e} 151$ which arises by loss of $\mathrm{CO}$ from the [M-15]+ fragment ion (11). In the mass spectrum of $p$-hydroxyphenylacetonitrile-TMS (Figure 3) the fragment at $\mathrm{m} / \mathrm{e} 116$ [M-89]+ corresponds to loss of $\mathrm{Me}_{3} \mathrm{SiO}$ (1). A similar [M-89]+ fragment ion is observed in several of the other mass spectra.

The mass spectrum of $p$-hydroxyphenylacetaldoxime-TMS 2 (Figure 4) contains an interesting ion at $\mathrm{m} / \mathrm{e} 253$ (Scheme 1). This ion is most likely formed by expulsion of $\mathrm{HCN}$ from the $[\mathrm{M}-15]^{+}$ion. The assigned structure was supported by exact mass measurement $\left(\mathrm{C}_{12} \mathrm{H}_{21} \mathrm{O}_{2} \mathrm{Si}_{2}\right.$ : calculated, 253.1080; found, 253.1088). Mass spectrometric fragmentation patterns of aldoximes (6) often show a [M-27]+ ion which could reflect a similar elimination of $\mathrm{HCN}$ from the parent ion.

The most important fragmentation process observed in the mass spectrum of tyramine$\mathrm{TMS}_{3}$ (Figure 5) is the removal of a valence electron of the nitrogen atom followed by cleavage of the adjacent carbon-carbon bond. This results in the fragment ion at $\mathrm{m} / \mathrm{e} 174$ (Scheme 2). The same process with an alternative molecular ion leads to the ion of $\mathrm{m} / \mathrm{e} 179$. As observed in the mass spectrum of tyramine$\mathrm{TMS}_{3}$, the spectrum of tyrosine-TMS 3 (Figure 6) also exhibits ions reflecting cleavage of the 
B. Lindberg Møller et al.: Cyanogenic glucoside biosynthesis

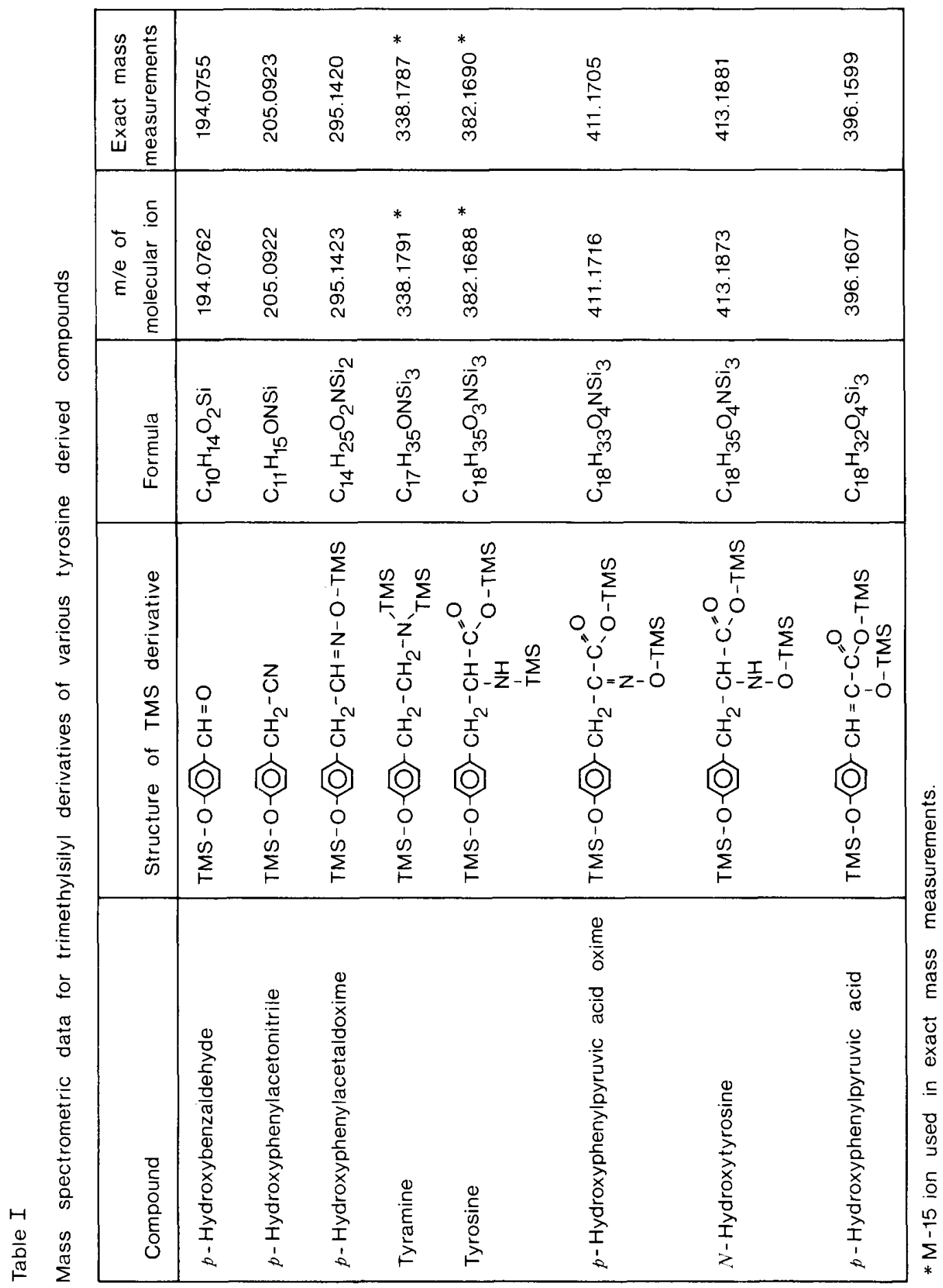


B. LiNDBerg Møller et al.: Cyanogenic glucoside biosynthesis

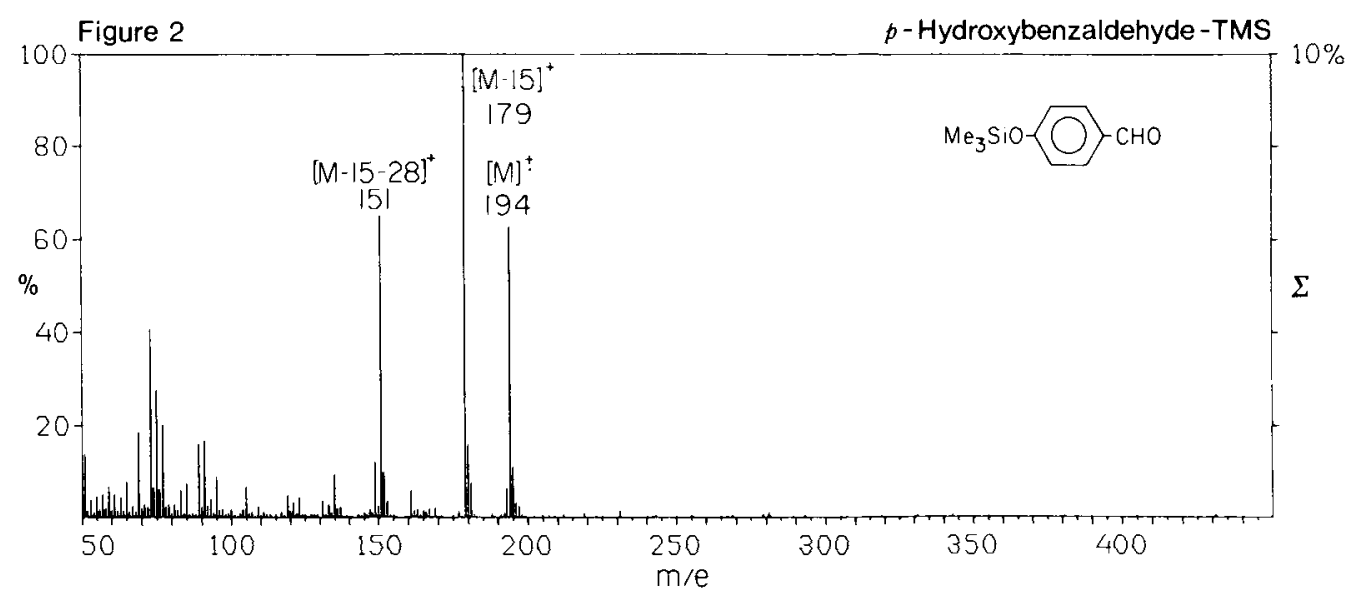

Figure 3

$p$ - Hydroxyphenylacetonitrile-TMS
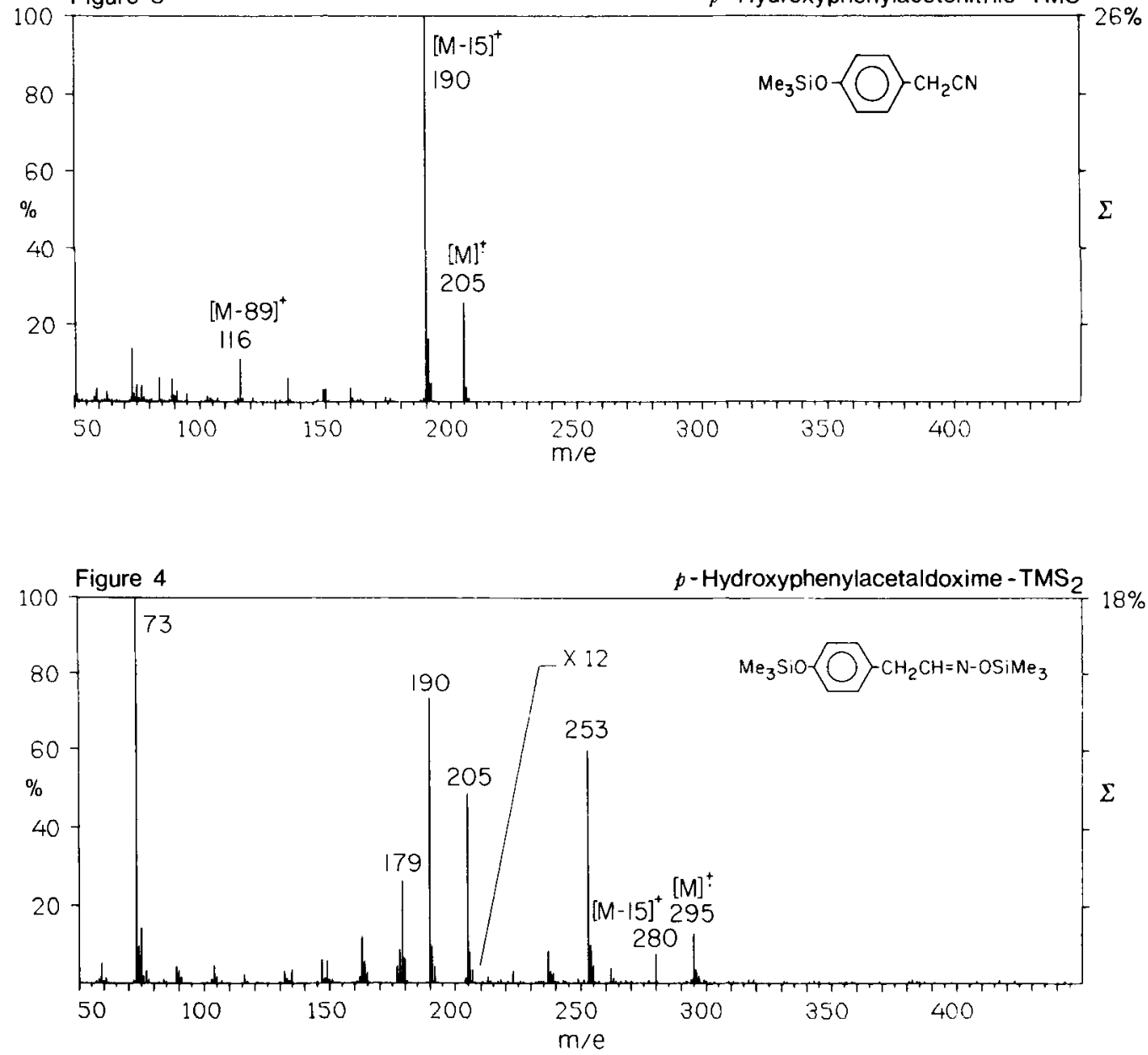

Figure 2-9. Mass spectra of the following trimethylsilylated compounds: $p$-hydroxybenzaldehyde, $p$ hydroxyphenylacetonitrile, $p$-hydroxyphenylacetaldoxime, tyramine, tyrosine, $p$-hydroxyphenylpyruvic acid oxime, $N$-hydroxytyrosine and $p$-hydroxyphenylpyruvic acid. 
B. Lindererg Mal.ter et al.: Cyanogenic glucoside biosynthesis
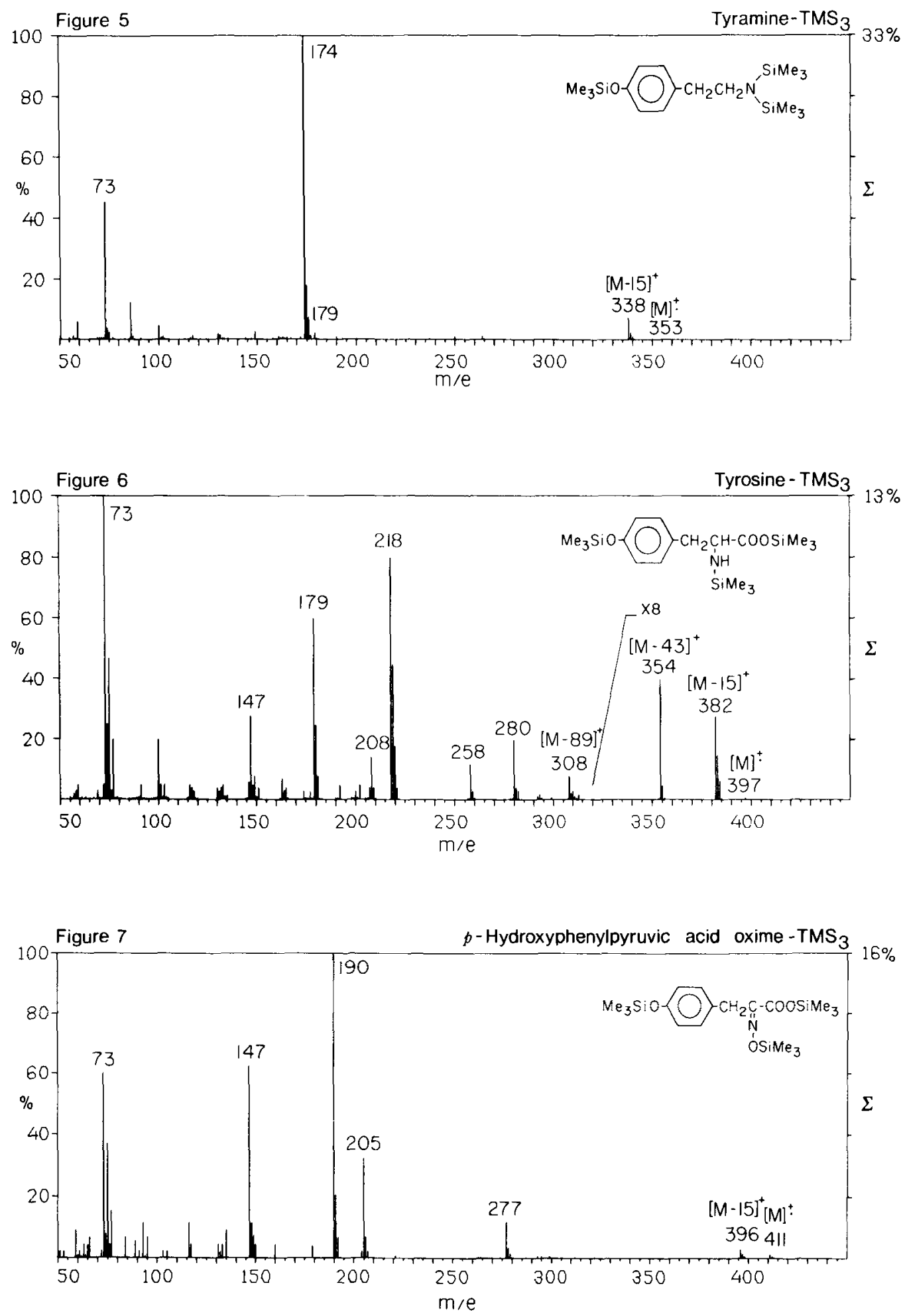
Scheme 1

Fragmentation scheme for trimethylsilylated $p$-hydroxyphenylacetaldoxime.

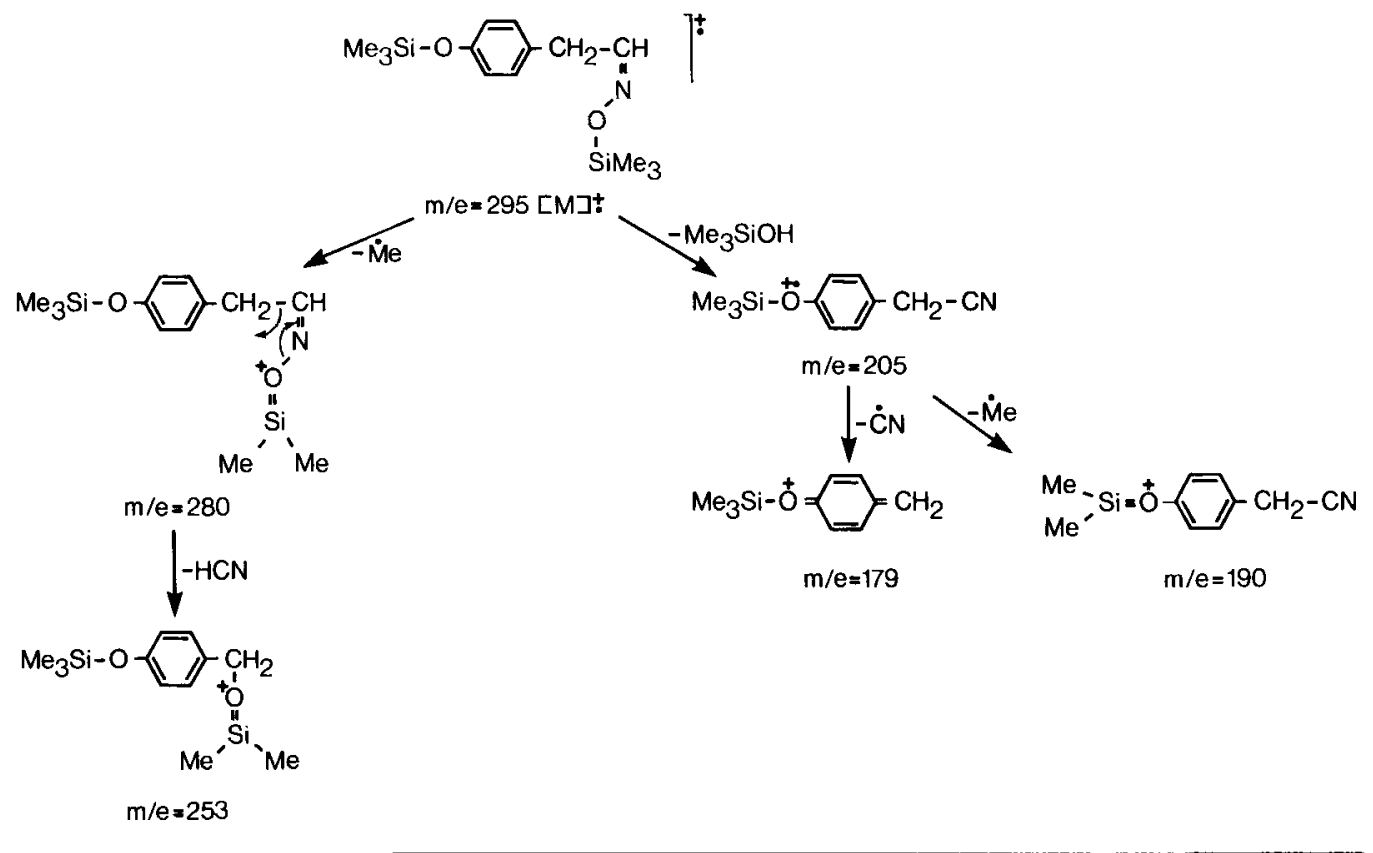

carbon-carbon bonds adjacent to the nitrogen atom (Scheme 3). The fragment ion at $\mathrm{m} / \mathrm{e} 354$ [M-43] + can be explained by the loss of a methyl radical followed by a rearrangement reaction involving loss of carbon monoxide (Scheme 3). A similar [M-43]+ fragment ion has been observed in mass spectra of other TMS-amino acids $(9$,

\section{Scheme 2}

Fragmentation scheme for trimethylsilylated tyramine.

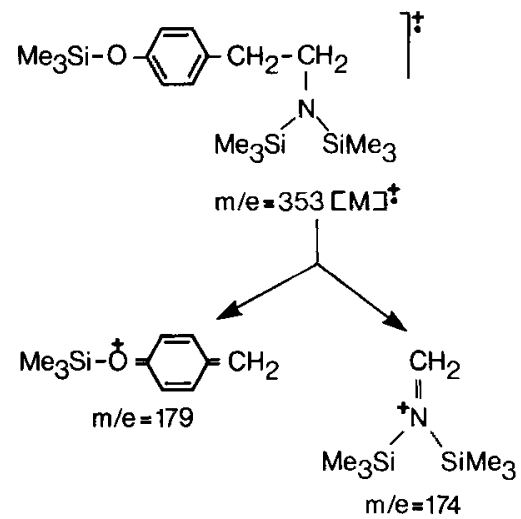

27). To support this rearrangement scheme, the exact mass of the fragment ion at $\mathrm{m} / \mathrm{e} 354$ was determined. The observed mass was 354.1760 which compares with the mass of 354.1741 for the predicted formula, $\mathrm{C}_{16} \mathrm{H}_{32} \mathrm{O}_{2} \mathrm{NSi}_{3}$. The computer reported four possible formulae with exact masses that were within 3 millimass units of the observed value and this was only the second best fit. The best fit was the formula $\mathrm{C}_{20} \mathrm{H}_{26} \mathrm{O}_{2} \mathrm{~N}_{2} \mathrm{Si}$ with a mass of 354.1764 . The formation of this ion would require an ion-molecule reaction because of the high number of carbon atoms present. No easily explainable mechanism for such a reaction was found and the formation of an ion with this composition seems highly unlikely. The other two formulae listed by the computer made no sense.

The mass spectrum of $p$-hydroxyphenylpyruvic acid oxime-TMS ${ }_{3}$ (Figure 7) contains $[\mathrm{M}]^{+}$ and $[\mathrm{M}-15]^{+}$and two strong ions at $\mathrm{m} / \mathrm{e} 205$ and 190 (Scheme 4). These are presumably formed by a pathway involving localization of the positive charge on the phenolic oxygen atom followed by a rearrangement involving the loss of $\mathrm{CO}_{2}$. Localization of the positive charge on the 
B. Lindberg Møller et al.: Cyanogenic glucoside biosynthesis

\section{Scheme 3}

Fragmentation scheme for trimethylsilylated tyrosine, accounting for ion at $\mathrm{m} / \mathrm{e} 354$ by rearrangement.

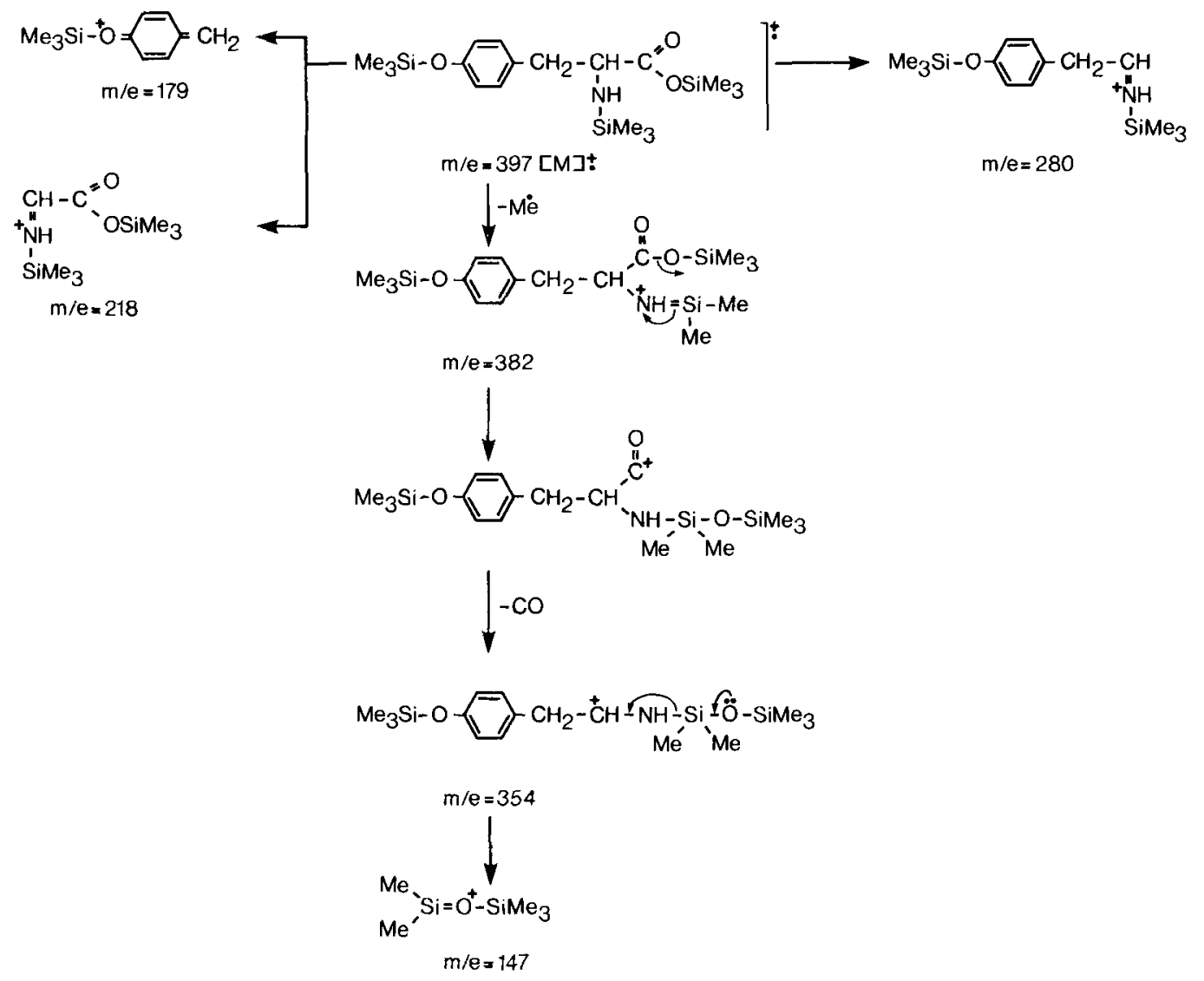

\section{Scheme 4}

Fragmentation scheme for trimethylsilylated $p$-hydroxy phenylpyruvic acid oxime involving a McLafferty-type rearraugement.

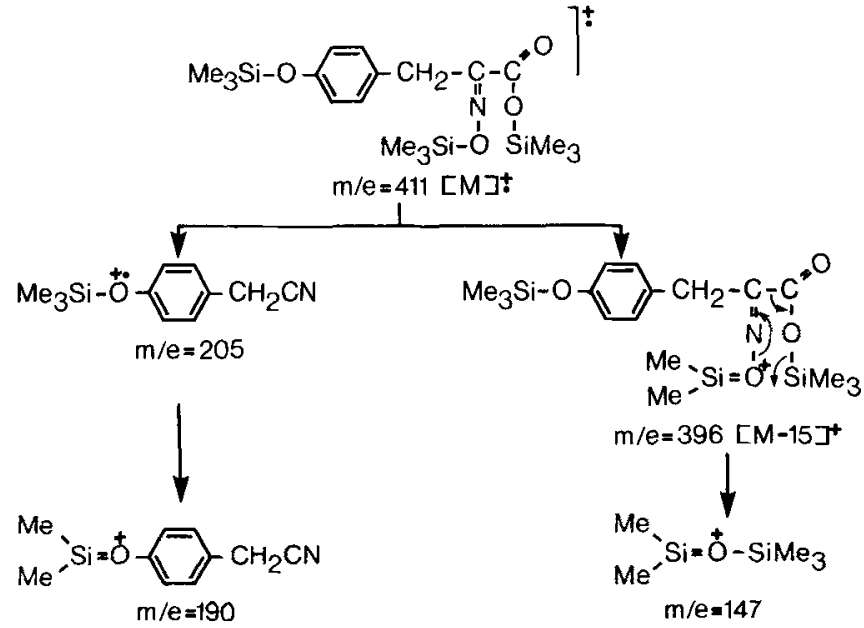

Carlsberg Res. Commun. Vol. 44, p. 367-379, 1979 


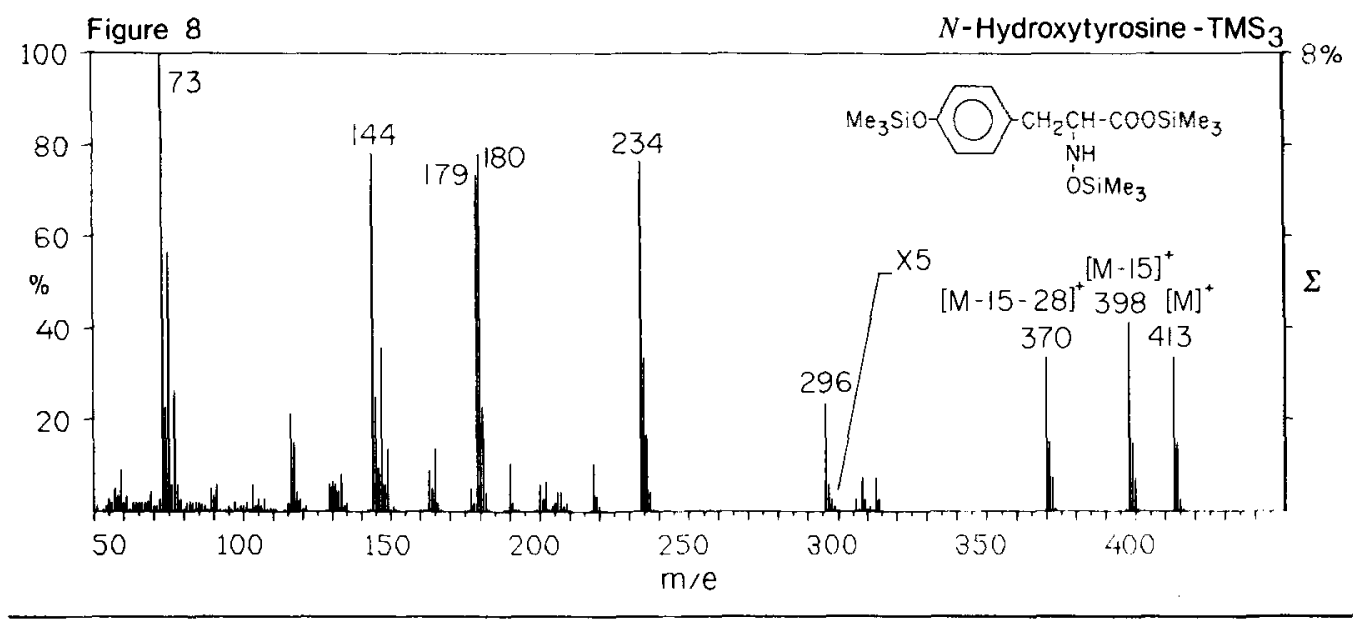

oxime oxygen atom followed by the loss of a methyl radical and rearrangement resuits in the strong ion at $\mathrm{m} / \mathrm{e} 147$.

The mass spectrum of $N$-hydroxytyrosine (Figure 8) is of special interest because mass spectrometric data have not previously been reported on TMS derivatives of $N$-hydroxyamino acids. Prominent fragmentation reactions in- volve cleavage of the carbon-carbon bonds adjacent to the nitrogen atom, leading to the fragment ions at $\mathrm{m} / \mathrm{e} 296,234,179$, and 144 (Scheme 5). The fragment ion at $\mathrm{m} / \mathrm{e} 370$ can be explained by a pathway with localization of the positive charge on the oxygen atom of the hydroxylamine function and loss of a methyl radical, followed by an intramolecular rearrange-

\section{Scheme 5}

Fragmentation scheme for trimethylsilylated $N$-hydroxytyrosine also accounting for the fragment ion at $\mathrm{m} / \mathrm{e}$ 370 by rearrangement.

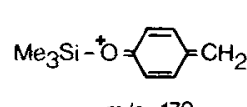

$\mathrm{m} / \mathrm{e}=179$<smiles>COC(=O)C(OC)OC</smiles>

$\mathrm{m} / \mathrm{e}=234$<smiles>COC(C#N)(C#N)CO[Na]</smiles>

$m / e=144$

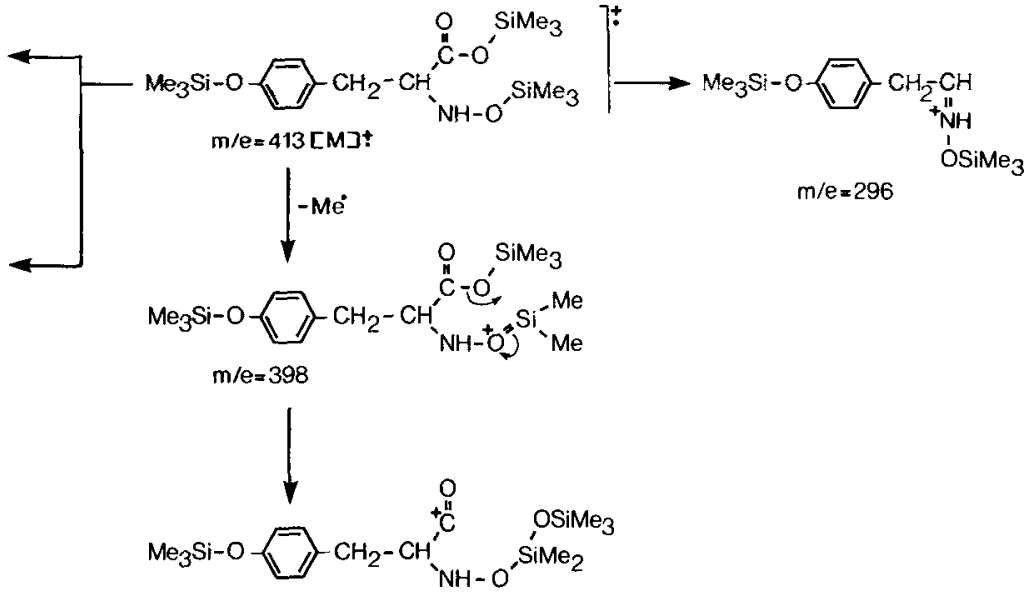<smiles>CC(C)C(C)C</smiles><smiles>C[Si]Oc1ccc(C[CH+]NCO[Si](C)(O[Si])O[Si](C)(C)C)cc1</smiles> 


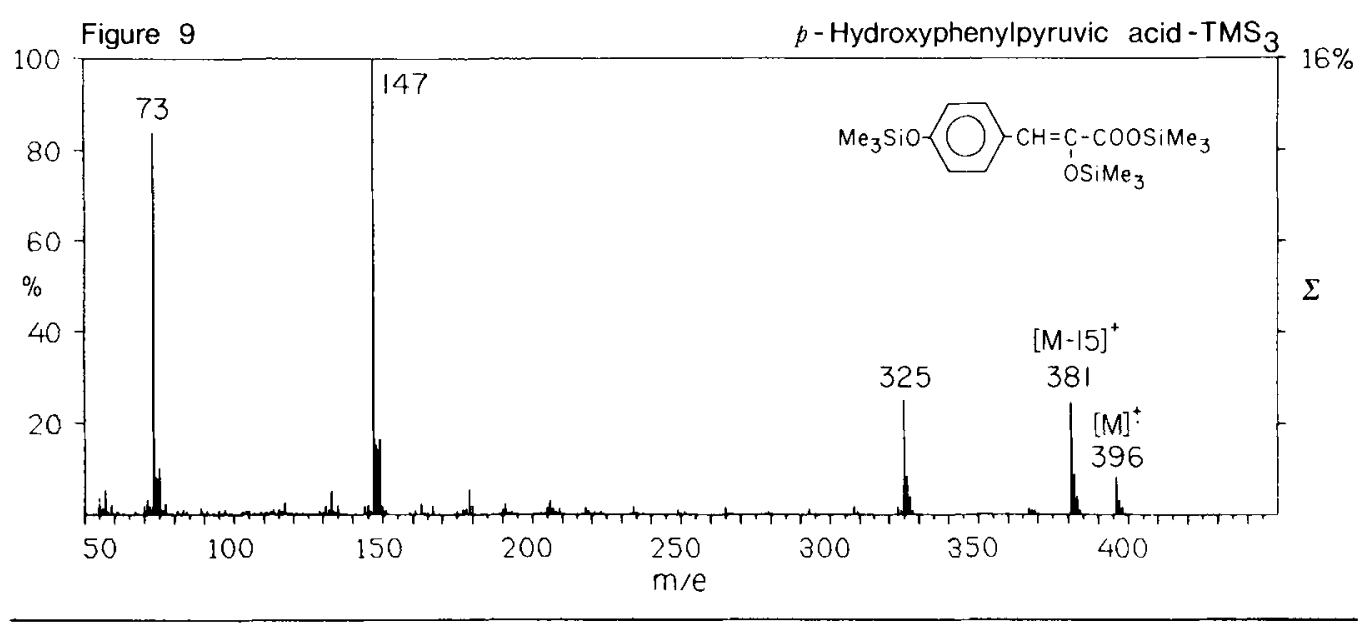

\section{Scheme 6}

Fragmentation scheme for trimethylsilyl derivative of the enol form of $p$-hydroxyphenylpyruvic acid.
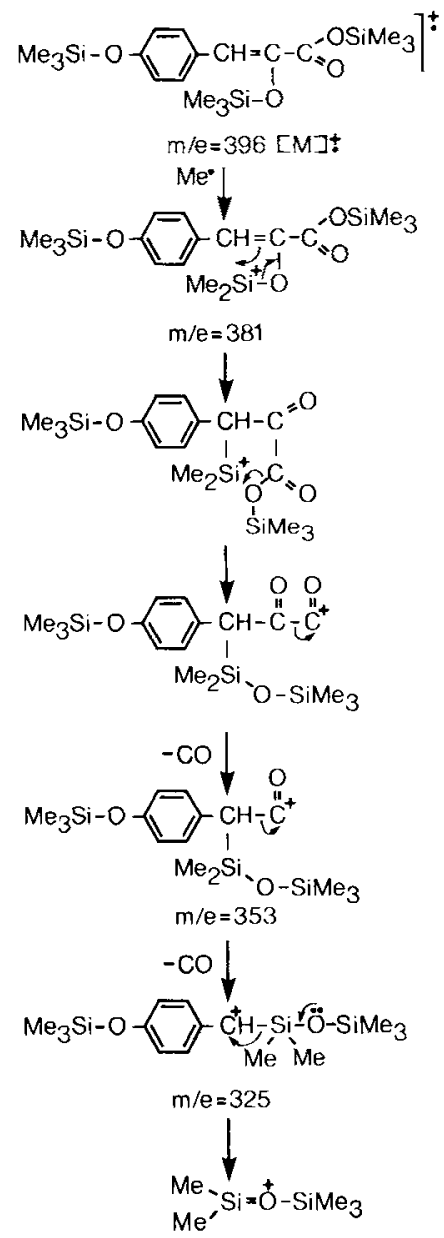

$\mathrm{m} / \mathrm{e}=147$ ment resulting in the loss of carbon monoxide (Scheme 5). The proposed fragmentation pathways are supported by exact mass measurements of the following ions: $\mathrm{m} / \mathrm{e} 370\left(\mathrm{C}_{16} \mathrm{H}_{32} \mathrm{O}_{3} \mathrm{NSi}_{3}\right.$ : calculated, 370.1690; found, 370.1676), m/e $234\left(\mathrm{C}_{8} \mathrm{H}_{20} \mathrm{O}_{3} \mathrm{NSi}_{2}\right.$ : calculated, 234.0981; found $234.0975)$ and $\mathrm{m} / \mathrm{e} 144\left(\mathrm{C}_{5} \mathrm{H}_{10} \mathrm{O}_{2} \mathrm{NSi}\right.$ : calculated, 144.0481; found 144.0475). For all three ions none of the other formulae listed by the computer made any sense.

In the mass spectrum of the trimethylsilyl derivative of $p$-hydroxyphenylpyruvic acid (Figure 9) a molecular ion at $\mathrm{m} / \mathrm{e} 396[\mathrm{M}]^{+}$and an $[\mathrm{M}-15]^{+}$ion at $\mathrm{m} / \mathrm{e} 381$ are observed. These ions correspond to a tris -(trimethylsilyl) derivative obtained by silylation of the enol form of $p$ hydroxyphenylpyruvic acid (7). The fragment ion at $\mathrm{m} / \mathrm{e} 325$ is believed to be formed by an intramolecular rearrangement reaction followed by sequential loss of two equivalents carbon monoxide (Scheme 6). This pathway also explains the predominant siloxonium ion observed at $\mathrm{m} / \mathrm{e} 147$. Exact mass measurements of $\mathrm{m} / \mathrm{e}$ 381 and 325 and measurements of metastable ions are in support of this fragmentation pathway. The computer listed eleven formulae with exact masses within three millimass units of the observed mass of 381.1368 for the $[\mathrm{M}-15]^{+}$ion. Only four of the calculated possibilities were devoid of nitrogen and one of these was 381.1373 for $\mathrm{C}_{17} \mathrm{H}_{29} \mathrm{O}_{4} \mathrm{Si}_{3}$, the predicted formula. The other three possibilities made no sense. Similarly, the ion at $\mathrm{m} / \mathrm{e} 325$ had an observed exact mass of 325.1461. This value was within three millimass units of four 
different formulae, one of which fits the predicted structure $\mathrm{C}_{15} \mathrm{H}_{29} \mathrm{O}_{2} \mathrm{Si}_{3}$ (m/e 325.1475$)$ while the other three formulae listed by the computer made no sense. Oscillographic recordings showed a metastable ion at $\mathrm{m} / \mathrm{e} 367$ as expected $\left(m^{*}, 366.6\right)$ for the conversion of $[M]^{+}$ to $[\mathrm{M}-15]^{+}$. A second metastable ion was observed at $\mathrm{m} / \mathrm{e} 278$, close to that predicted $\left(\mathrm{m}^{*}\right.$, 277.2) for conversion of $\mathrm{m} / \mathrm{e} 381$ to 325 . If direct conversion of $[\mathrm{M}]+$ to $\mathrm{m} / \mathrm{e} 324 \mathrm{had}$ occurred a putative metastable ion would have been observed at $\left(\mathrm{m}^{*}, 266.7\right)$.

\section{CONCLUSION}

The mass spectrometry data here presented were successfully used to identify intermediates of the biosynthesis of the cyanogenic glucoside dhurrin obtained from the biological mixtures. When L-tyrosine was used as a substrate for the microsomal system, the following intermediates could, after initial purification by TLC, be unambiguously identified by use of the GLC-MS procedure: $p$-hydroxyphenylacetaldoxime, $p$-hydroxyphenylacetonitrile, and $p$-hydroxybenzaldehyde. Previously, the formation of these compounds and their relation to cyanogenic glucoside biosynthesis were indicated only by TLC studies and by recrystallization of radioactively labelled material to constant specific activity with authentic unlabelled carriers $(17,24)$. As indicated by the trial experiments with $\mathrm{L}-\left[\mathrm{U}-{ }^{14} \mathrm{C}\right]$ tyrosine, it was generally not possible to demonstrate the formation of $N$-hydroxytyrosine in the microsomal incubation mixtures. This may be related to the catalysis of the biosynthetic pathway by two multienzyme complexes or by two multifunctional proteins (18). The accumulation of $N$-hydroxytyrosine is only observed in experiments where unlabelled $N$-hydroxytyrosine carrier is added (17). The formation of $N$-hydroxytyrosine from tyrosine under such conditions could perhaps be unambiguously demonstrated by use of the GLC-MS procedure combined with the use of stable isotopes.

The method described was developed to identify intermediates involved in the biosynthesis of the cyanogenic glucoside dhurrin. Since the GLC system used also permits the separation of intermediates implicated in the biosynthesis of other cyanogenic glucosides (15) it will be possible to identify these intermediates by mass spectrometry and the method should therefore prove to be of general use.

\section{ACKNOWLEDGEMENTS}

Dr. Bernd SoltmanN is thanked for doing the high resolution mass spectrometry analyses, Dr. C. E. OLSEN for critically reviewing the manuscript, Nina Rasmussen for drawing the fragmentation schemes, ANN-Sofl SteInHoltz for photography work, and HANNE THEM NIELSEN for typing the manuscript. This project was supported in part by the Danish Natural Science Research Council grant 511-3988 (BLM), by a Fullbright-Hays Act fellowship (BLM), by NIH grant RP-00840 (CCS), by NSF grant BMS-7411997 (EEC), and by USPHS grant GM-05301 (EEC).

\section{REFERENCES}

1. Budzikiewicz, K., C. Djerassi \& D. H. WiLuAMs: Trimethylsilyl ethers. Mass Spectrometry of Organic Compounds, Holden-Day, Inc., San Francisco, Cambridge, New York, London, Amsterdam, pp. 471-479 (1967)

2. Conn, E. E.: Cyanogenic glucosides. J. Agric. Food Chem. 17, 519-526 (1969)

3. CONN, E. E. \& G. W. ButLer: The biosynthesis of cyanogenic glucosides and other simple nitrogen compounds. In: Perspectives in Phytochemistry (eds. J. B. Harborne \& T. Swain) Academic Press, London and New York, pp. 47-74 (1969)

4. Dejongh, D. C., T. Radford, J. D. Hribar, S. Hanessian, M. Bieger, G. Dawson \& C. C. SwEeleY: Analysis of trimethylsilyl derivatives of carbohydrates by gas chromatography and mass spectrometry. J. Am. Chem. Soc. 91, 1728-1740 (1969)

5. Diekman, J., J. B. Thomson \& C. Djerassi: Mass spectrometry in structural and stereochemical problems. CLV. Electron impact induced fragmentations and rearrangements of some trimethylsilyl ethers of aliphatic glycols and related compounds. J. Org. Chem. 33, 2271-2284 (1968)

6. Goldsmith, D., D. Becher, S. SAmple \& C. DJERASSI: Mass spectrometry in structural and stereochemical problems-XCVII. A study of the fragmentation processes of oximes. Tetrahedron, Suppl. 7, 145-173 (1966) 
7. Hoffman, N. E., A. M. Milling \& D. PARMelge: Infrared, nuclear magnetic, and ultraviolet spectral and gas chromatographic properties of some aromatic acid trimethylsilyl derivatives. Anal. Biochem. 32, 386-395 (1969)

8. Kosuge, T., M. G. Heskett \& E. E. Wilson: Microbial synthesis and degradation of indole-3acetic acid. I. The conversion of L-tryptophan to indole-3-acetamide by an enzyme system from Pseudomonas savastanoi. J. Biol. Chem. 241, 3738-3744 (1966)

9. Lawson, A. M., D. B. Ramsden, P. J. Raw \& R. HOFFENBERG: Mass spectrometric studies of thyroxine and related compounds. Trimethylsilyl derivatives. Biomedical Mass Spectrometry 1, 374-380 (1974)

10. Mazelis, M. \& L. L. Ingraham: The pyridoxal phosphate-dependent oxidative decarboxylation of methionine by peroxidase. II. Identification of 3-methyl-thiopropionamide as a product of the reaction. J. Biol. Chem. 237, 109-112 (1962)

11. McCollum, J. D. \& S. Meyerson: Organic ions in the gas phase. $X$. Decomposition of benzaldehyde under electron impact. J. Amer. Chem. Soc. 85, 1739-1741 (1963)

12. McFarlane, I. J., E. M. Lees \& E. E. Conn: The in vitro biosynthesis of dhurrin, the cyanogenic glucoside of Sorghum bicolor. J. Biol. Chem. 250, 4708-4713 (1975)

13. Meister, A: Decarboxylases. Biochemistry of the Amino Acids, Volume I, 2nd ed., Academic Press, New York, London, pp. 325-338 (1965)

14. Meister, A.: Oxidative deamination. Biochemistry of the Amino Acids, Volume I, 2nd ed., Academic Press, New York, London, pp. 294319 (1965)

15. MøLleR, B. L.: Intermediates in the biosynthesis of cyanogenic glucosides determined by use of gas chromatograph coupled with a gas proportional counter. Anal. Biochem. 81, 292-304 (1977)

16. Møller, B. L.: Chemical synthesis of labelled intermediates in cyanogenic glucoside biosynthesis. J. Labelled Compounds Radiopharmaceuticals 14, 663-671 (1977)

17. Meller, B. L. \& E. E. Conn: The biosynthesis of cyanogenic glucosides in higher plants. $\mathrm{N}$ Hydroxytyrosine as an intermediate in the biosynthesis of dhurrin by Sorghum bicolor (Linn) Moench. J. Biol. Chem. 254, 8575-8583 (1979)

18. Møller, B. L. \& E. E. Conn: The biosynthesis of cyanogenic glucosides in higher plants. Channeling of intermediates in dhurrin biosynthesis by a microsomal system from Sorghum bicolor (Linn) Moench. J. Biol. Chem. (in press)

19. Møller, B. L., E. E. Conn, F. Martin \& C. C. SwEELEY: Biosynthesis of the cyanogenic glucoside dhurrin studied by stable isotope labelling. 1 lth FEBS Meeting. August 14-19, 1977, Copenhagen, Abstract LB 400

20. Møller, B. L., I. J. McFarlane \& E. E. Conn: Chemical synthesis and disproportionation of $N$ hydroxytyrosine. Acta Chem. Scand. B 31, 343344 (1977)

21. Pierce, A. E.: Amino acids and related compounds. Silylation of Organic Compounds. Pierce Chemical Company, Rockford, Ill pp. 218-222 (1968)

22. Reay, P. F. \& E. E. ConN: The purification and properties of a uridine diphosphate glucose: aldehyde cyanohydrin $\beta$-glucosyltransferase from Sorghum seedlings. J. Biol. Chem. 249, 5826-5830 (1974)

23. Seely, M. K., R. S. Criddle \& E. E. Conn: The metabolism of aromatic compounds in higher plants. VIII. On the requirement of hydroxynitrile lyase for flavin. J. Biol. Chem. 241, 44574462 (1966)

24. Shimada, M. \& E. E. Conn: The enzymatic conversion of $p$-hydroxyphenylacetaldoxime to $p$-hydroxymandelonitrile. Arch. Biochem. Biophys. 180, 199-207 (1977)

25. Takeda, H., S. Yamamoto, Y. Kojima \& O Hayalshi: Studies on monooxygenases. I. General properties of crystalline L-lysine monooxygenase. J. Biol. Bhem. 244, 2935-2941 (1969)

26. Thoal, N. V. \& A. OlomuckI: Arginine décarboxy-oxydase. I. Charactères et nature de l'enzyme. Biochim. Biophys. Acta 59, 533-544 (1969)

27. Vandenheuvel, W. J. A. \& J. S. Cohen: Gasliquid chromatography-mass spectrometry of carbon- 13 enriched amino acids as trimethylsilyl derivatives. Biochim. Biophys. Acta 208, 251$259(1970)$ 